\title{
Construction mediation and its hybridization: the case of the Hong Kong construction industry
}

DOI 10.1515/otmcj-2016-0015

Received December 15, 2016; accepted May 10, 2017

Abstract: In view of the sophisticated nature of construction disputes, specialized dispute resolution mechanisms are of pivotal importance to the satisfactory settlement between disputing parties. Among the various construction dispute resolution mechanisms, mediation has been increasingly gaining recognition and acceptance. Its hybrid, namely mediation-arbitration (med-arb), has also emerged and has started receiving attention and appreciation. With special reference to the construction industry practice in Hong Kong, a commentary on the respective merits and demerits of construction mediation and construction med-arb, as well as the ways forward, are presented in this article.

Keywords: alternative dispute resolution, construction mediation, mediation-arbitration, specialized facilitative mediation

\section{Introduction}

Disputes in the construction industry are of high complexity compared with other disputes in general. The underlying reasons hinge on the peculiarities of the construction industry, which is characterized by the adoption of multilevel subcontracting system, involvement of multiple contracting parties and stakeholders (owner, main contractor, subcontractors, nominated subcontractors,

\footnotetext{
*Corresponding author: Pui-Lam Ng, Faculty of Civil Engineering, Vilnius Gediminas Technical University, Vilnius, Lithuania, E-mail: irdngpl@gmail.com

Pui-Lam Ng, Department of Civil Engineering, The University of Hong Kong, Hong Kong, China; Faculty of Civil Engineering, Vilnius Gediminas Technical University, Vilnius, Lithuania Audrius Banaitis, Department of Construction Economics and Property Management, Vilnius Gediminas Technical University, Vilnius, Lithuania
}

consultants, material suppliers, and so on), variable contractual arrangements (such as Designer-Led, Design-andBuild, Design-Construct-Operate, and Turnkey), variable measurement and payment methods (such as Lump sum, Fixed price, Fixed Bills of Quantities, Schedule of Rates with remeasurement, and Target cost) (Banaitienè and Banaitis 2012), prevalence of power issues, large scale of projects, absence of verbose statutory control, and - last but not least - the pervasion of highly technical knowledge and expertise. Figure 1 depicts the various participants in a typical construction project.

In legal proceedings, it is commonplace to have experts in specific areas of construction field to enlighten the court. In alternative dispute resolution (ADR), it is imperative for the neutral party to be capable of understanding the subject matter: first of all to comprehend the subject under dispute and the discourse with and between the disputing parties (Chee 2013). Therefore, it is important that the resolution of construction disputes should be specialized rather than treated in the same generic manner as disputes in other sectors such as consumer affairs, finance, marine, property management, family, and so on. (some of these may be worth specialization in their own right).

Different mechanisms of dispute resolutions, namely litigation, arbitration, adjudication, mediation, conciliation, expert determination, dispute resolution advisor, and dispute review board/panel (save litigation, all the others fall into the realm of ADR), are available (Cheng and Soo 2013; Construction Industry Council 2015; Levin 2016). Among these mechanisms, mediation has been increasingly gaining recognition and acceptance among construction practitioners (Richbell 2008; Chee 2013; Cheung 2014) and has been identified as the preferred method of facilitative dispute resolution by means of the multicriteria negotiation decision support system (Kaklauskas et al. 2008). Mediation has been incorporated in the Hong Kong Government's General Conditions of Contract (Hong Kong Government 1985, 1993, 1999) and has been strongly promulgated by various learned societies in the industry. The recently enacted Mediation Ordinance in Hong Kong (Hong Kong Government 2013) has provided a 


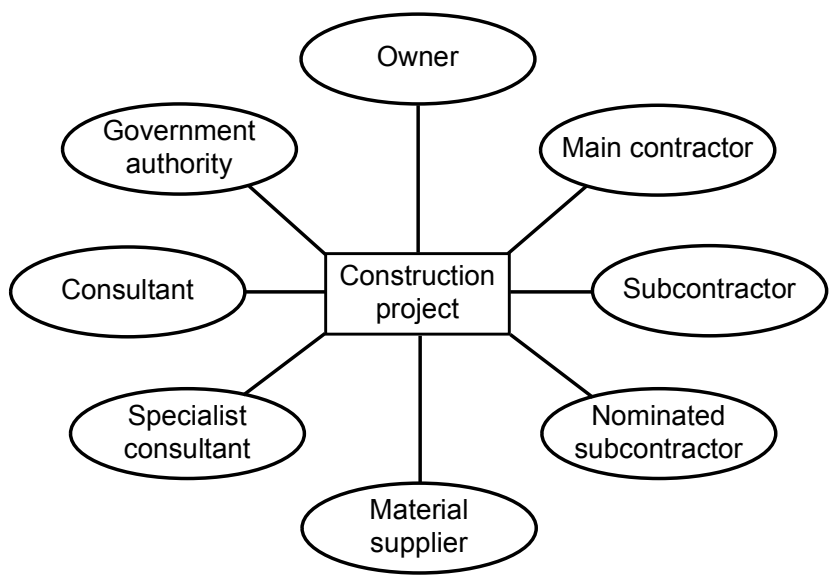

Fig. 1: Contracting parties and stakeholders of a construction project.

statutory framework for the conduct of mediation. In addition, a hybrid dispute resolution mechanism, mediationarbitration (med-arb) (Oghigian 2003) has also emerged and has been innovatively attempted in the field.

The primary objective of this study therefore is to analyze construction mediation and its hybrid with arbitration, namely, construction med-arb, as an emerging dispute resolution mechanism. The study encompasses the nature, key features, pros, and cons of mediation and med-arb, with special reference to the Hong Kong construction industry. The authors opine that both mediation and med-arb have good prospects in resolving construction disputes, helping construction projects to reach completion on time and within budget, and with minimal interruption and aggravation, as detailed in the commentary hereunder.

The remainder of this article is structured as follows. Section 2 presents the nature of construction disputes. Section 3 discusses construction mediation. Section 4 gives an account of construction med-arb. Finally, concluding remarks are provided in Section 5.

\section{Nature of construction disputes}

From an analysis of vast cases in the construction industry, there are different types of construction disputes, as listed and exemplified in the following:

1. Contractual disputes such as contradictory requirements, ambiguous/unspecific requirements (e.g., "to the satisfaction of the Engineer"), inconsistent specifications, missing items, and unforeseeable items.

2. Commercial disputes such as delayed payments, withheld payments, and nonpayments.
3. Technical disputes such as noncomplying performance with regard to contract drawings and specifications that sometimes may contain irrational and unachievable requirements by a reasonably competent, diligent, and resourceful contractor.

4. Professional disputes such as nonobservance on professional conducts, ethics, good practice, or guidelines.

5. Legal disputes such as noncomplying actions or nonactions by law, wherein prosecution has to be initiated by the involved parties.

Looking into the substance of construction disputes, Kumaraswamy (1998) identified a comprehensive list of cost and time claim categories, as depicted in Tables 1 and 2, to cover construction disputes in a broad sense with special reference to the Hong Kong industry. Nonetheless, these findings are applicable to the construction industries in many parts of the world.

In essence, construction disputes are commonly centered on one or more than one of the following elements:

1. Extension of Time (E.O.T.), Liquidated Damages (L.D.), and Prolongation;

2. Contract variation, inclusive of Variation Order (V.O.) and Engineer's Instruction (E.I.);

3. Scope of works, hidden work, and additional work;

4. Defects, noncompliance, and outstanding works;

5. Interim payment (I.P.), and disallowed cost;

6. Practical completion (P.C.) or substantial completion.

\section{Construction mediation}

\subsection{Key features of construction mediation}

Mediation may be denoted as a consensual process in which a neutral third party, called the mediator, works with the disputing parties to help them explore, and if appropriate, reach a mutually acceptable resolution of some or all of the issues in dispute (Richbell 2008; Cheng and Soo 2013).

The key features of mediation are as follows:

1. Voluntary - The disputing parties enter into the mediation based on their own will. They enjoy party autonomy on selecting the mediator, mediation procedures, and mediation rules. They can make decisions in bargaining and negotiating during the mediation, and can even exit from the mediation voluntarily. 
Tab. 1: Cost claim categories.

\begin{tabular}{|c|c|}
\hline Category & Description \\
\hline CC 1 & Ambiguity in documents \\
\hline CC 2 & $\begin{array}{l}\text { Construction method change due to Engineer's comments } \\
\text { (on Contractor's method statement) }\end{array}$ \\
\hline CC 3 & Error in setting out due to incorrect data shown on drawings \\
\hline CC 4 & Rectification of damage caused by excepted risks \\
\hline CC 5 & Disposal of fossils \\
\hline CC 6 & Facilities provided to other contractors, in excess of those anticipated at the tender stage \\
\hline CC 7 & Additional tests (to verify compliance with specifications, in excess of those anticipated at the tender stage) \\
\hline CC 8 & Uncovering of works for examination \\
\hline CC 9 & Delayed possession of works \\
\hline CC 10 & Acceleration of works \\
\hline CC 11 & Suspension of works \\
\hline CC 12 & Additional work (to other parts of the works) arising from repairs or defects \\
\hline CC 13 & Investigation of alleged defects \\
\hline CC 14 & Interest on claims due to their late valuation \\
\hline CC 15 & Disruption to regular progress due to: \\
\hline CC $15 \mathrm{~A}$ & - late instructions \\
\hline CC 15B & - variations \\
\hline CC $15 \mathrm{C}$ & - opening for inspection \\
\hline CC 15D & - delay caused by any person or organization employed by the Employer \\
\hline CC 15E & - late delivery of materials by the Employer \\
\hline CC 16 & Employer's breach of contract \\
\hline CC 17 & Variations (including Engineer's instruction to change) \\
\hline CC 18 & $\underline{\text { Other reasons }}$ \\
\hline CC 18A & $\begin{array}{l}\text { - Delay caused by additional/unforeseen government departmental } \\
\text { procedures and late issue of consent }\end{array}$ \\
\hline CC $18 \mathrm{~B}$ & - Overbreaks on cutting slopes \\
\hline $\mathrm{CC} 18 \mathrm{~B}+\mathrm{CC} 18 \mathrm{C}$ & - Delays caused by unforeseeable obstructions to foundation constructions \\
\hline CC minor & $\begin{array}{l}\text { - Delays due to variations } \\
\text { - Incorporation of categories where claims were relatively "minor" }\end{array}$ \\
\hline
\end{tabular}

Tab. 2: Time claim categories.

\begin{tabular}{ll}
\hline Category & Description \\
\hline TC 1 & Inclement weather \\
TC 2 & Hoisting of typhoon signal no. 8 or above \\
TC 3 & Instruction issued to resolve discrepancy \\
TC 4 & Variation Order \\
TC 5 & Substantial increase in quantity of any work item not resulting from a variation \\
TC 6 & Delayed possession of site \\
TC 7 & Disruption to regular progress due to: \\
TC 7A & - late instructions \\
TC 7B & - variations \\
TC 7C & - opening for inspection \\
TC 7D & - delay caused by any person or organization employed by the Employer \\
TC 7E & - late delivery of materials by the Employer \\
TC 8 & Suspension of works by the Employer \\
TC 9 & Delay caused by an utility services organization \\
TC 10 & Excepted risks \\
TC 11 & Any other special circumstances \\
TC 11A & - Disruption to regular progress due to additional/unforeseen government departmental procedures, or late consent \\
TC 11B & - Disruption to regular progress due to unforeseeable obstructions \\
\hline
\end{tabular}


2. Nonbinding - The resolution between the disputing parties is not legally binding, and violation of the resolution may lead to another dispute but not a criminal offence. Nonetheless, the parties may sign the mediation agreement to form a supplementary agreement to the contract, which has a binding effect.

3. Confidential - All information arising out of or in connection with the mediation shall be kept confidential, and any information disclosed in confidence to the mediator by a party shall not be disclosed to the other party without prior permission.

4. Private - The information and agreement arising from mediation shall be entirely private. The mediated agreement will not be contributory to the Case Law and will not establish any precedent for future cases.

5. Neutrality - The mediator shall be independent, neutral, and shall avoid possible conflicts of interest in connection with the parties and the outcome of mediation; and the mediator shall conduct the mediation in an impartial manner.

6. Facilitative - The prime role of the mediator is to assist the parties to identify the issues in disputes, to explore and generate options, to communicate and negotiate, and to reach a mutually satisfactory agreement. Such facilitative approach is in contrast to the evaluative approach, wherein the neutral party may evaluate the quantum of claims and the relative merits, as well as give advice, opinion, or views in the middle of the ADR process.

7. Structured - The mediation process is composed of (1) convening, (2) opening, (3) communication, (4) negotiation, and (5) closing stages, and the parties are informed about the process. During the communication and negotiation stages, the mediator conducts joint sessions and private sessions (caucuses) and exercises shuttle diplomacy to promote the parties reaching a common agreement.

8. Nonprejudicial - All documents, communication and information disclosed or produced through the mediation process shall be disclosed on a privileged and without-prejudice basis.

9. Interest-based - Mediation recognizes and addresses the needs, interests, and views of each party. This is in contrast to the rights-based dispute resolution mechanisms, wherein the rights and liabilities of the parties are evaluated.

10. Nonadjudicative - The mediator assumes a facilitative role in the mediation process and should not investigate the case, interrogate the parties, express opinions, and give judgment or verdict.

\subsection{Development of construction mediation in Hong Kong}

The development of construction mediation in Hong Kong dates back to 1982, when the draft mediation rules were prepared by the government (Kumaraswamy and Soo 2010). In 1984, a trial mediation scheme for selected civil engineering contracts was initiated, and the mediation rules were revised thereafter, leading to the incorporation of the mediation option in all public works contract in 1989 and issuance of Hong Kong Government Mediation Rules in 1991 (Hong Kong Government 1991). The Works Branch Technical Circulars 10/84, 8/89, and 11/91 (Hong Kong Government 1984, 1989, and 1991), respectively, set out administrative guidelines for trial mediation scheme, provided administrative guidelines for mediating construction disputes, and recommended mediation as an option to resolve construction disputes (Chau 2007). In the Hong Kong Government's General Conditions of Contract 1985 Edition and its subsequent versions (Hong Kong Government 1985, 1993, and 1999), both mediation and arbitration were incorporated as the dispute settlement mechanisms. It is stated in the General Conditions of Contract that any dispute matter should first be brought to mediation; if the matter cannot be resolved by mediation or if either party does not wish to mediate, then the dispute matter should be brought to arbitration. To cater for the special needs of the megascale construction of the Hong Kong International Airport and its associated infrastructure under the Airport Core Program (ACP), the ACP dispute resolution rules with provision of compulsory mediation were formulated in 1992 accompanying the ACP contracts.

Professional bodies of ADR have emerged in the past decades. The Hong Kong International Arbitration Centre (HKIAC) was set up in 1985, and it issued its own mediation rules in 1991 (revised in 1999). The Hong Kong Mediation Council was started as a division of HKIAC in 1994 and later became a single entity. The Hong Kong Construction Arbitration Centre (HKCAC) was established in 2006. It launched the HKCAC Mediation Rules specialized in construction in 2009 (revised in 2015) and manages the HKCAC List of Construction Mediators. Other learned societies in the industry also acted in response to the growing need for mediation. The Hong Kong Institution of Engineers (HKIE) was authorized by the Hong Kong Government to administer the mediation for public works contracts since 1984 until the government transferred the administration to HKIAC in 1991. In 2003, the HKIE established the Alternative Dispute Resolution Committee and manages an Internal List of HKIE Arbitrators and Mediators. The Hong Kong 
Institute of Construction Managers (HKICM) recently set up the Mediation Working Group in 2010 and established the HKICM Accredited Mediator List. The Hong Kong Institute of Architects (HKIA) established the Contract and Dispute Resolution Committee in its organization and maintains the List of HKIA Mediators. In the Agreement and Schedule of Conditions of Building Contracts, 2005 Edition, jointly published by HKIA/HKICM/HKIS (HKIA, HKICM, HKIS 2005), the mediation clause has been incorporated as part of the dispute resolution clauses. The Hong Kong Institute of Surveyors (HKIS) has joint efforts with the HKIA in operating the Joint Dispute Resolution Committee responsible for managing the HKIA/HKIS Joint Panel of Mediators.

The Civil Justice Reform (CJR) in 2009 was a catalyst for the blossom of mediation in Hong Kong. Practice Direction 31 was promulgated in 2009, and it governed the use of mediation, with exception in specific areas, including construction; whereas Practice Direction 6.1, dated February 2009, specifically addressed construction arbitration and mediation. Under the Practice Directions, the Court may impose adverse cost orders on parties that refused to mediate without reasonable explanation, and legal representatives may also face cost orders for failure to advise a client properly on the use of mediation. At the policy level, the Hong Kong Government launched a public consultation on mediation in 2010. The Mediation Bill was gazetted in 2011, and upon the completion of legislation process, the Mediation Ordinance (Chapter 620) was enacted in 2013 (Hong Kong Government 2013). The Mediation Ordinance sets out the statutory framework for the conduct of mediation and further confirms the role and prominence of mediation in the realm of ADR.

\subsection{Pros and cons of construction mediation}

The advantages of mediation in general are manifold and are attractive in the eyes of construction professionals in Hong Kong (Cheung 2014). Following is an elucidation of the advantages.

1. Time and cost savings - Mediation can take place quickly and often with relatively little expense, in contrast to resorting the dispute to court, tribunal, or arbitration. Such time and cost savings are particularly significant from the perspectives of small- to medium-sized market players, such as local consulting firms and subcontractors, as well as for disputes arising from small- to medium-scale construction contracts and subcontracts. Most commercial mediations are conducted over the course of 1 day, although some may extend over several days, weeks, or even months. There are enormous time and cost savings compared to a trial that may last for years.

2. Coverage of parties' interests - Mediation focuses on the parties' real commercial, emotional, and psychological needs and not just on their legal rights. As mentioned earlier, it is often true that construction contracts may contain problems of missing or unforeseeable items, as well as contradictory, ambiguous, or inappropriate requirements, under which the respective legal rights could be difficult to evaluate or define. The coverage of parties' interests by mediation addresses the needs of the construction industry.

3. Facilitated communication - Mediation encourages the parties to exchange views and communicate to each other frankly and allows the parties to communicate comfortably through the mediator on issues that they may be unwilling to talk about by themselves. Effective and open communication is one of the key success factors to resolve disputes. In the male-dominated construction industry, wherein daily communication is relatively inclined toward the technical and evaluative aspects, the mediator-promoted effective communication may inject momentum and vibrancy to the dispute resolution.

4. High degree of privacy - Mediation is private and confidential. In other words, sensitive matters or information will not become public during and after the mediation process. The reputation of the disputing parties is not at risk. This is an important point of consideration by construction-related companies, whose business prospect is strongly related to their past performance, job reference, and profile.

5. High degree of party autonomy - Mediation gives the parties an opportunity to choose the mediation rule and mediator, participate directly and informally in resolving their own dispute, and exercise control over the process itself and the outcome. Hence, the parties are likely to be committed to the outcomes produced by mediation. This matches the expectation of construction practitioners, who in general are to certain extent knowledgeable in handling disputes.

6. Sustainability of relationships - Mediation can eliminate the potential conflict and hostility that accompany the compulsory decision of the dispute by a court, tribunal, or arbitrator. Through the discourse during mediation, the mutual understanding between parties may be improved, which is conducive to sustaining their ongoing relationship. This merit bears 
strong relevance to the construction industry, where long-term business relationship is treasured.

7. Promotion of win-win results - Mediation can help the parties to explore new possibilities, generate options, and achieve win-win solutions. Through the creation of new options and interests, a zero-sum game may be transformed to a positive-sum game. The disputing parties may thus enjoy win-win or multiple-win results. As construction disputes are usually complex and involve multiple issues and interests, they may be better handled by expanding the pie that mediation could offer, rather than simply by a positional bargaining or judgmental approach.

On the other hand, mediation does come with a number of disadvantages that may deter its industry-wide application by construction professionals. These disadvantages may be overcome, or at least minimized, by appropriate practice, as explained in the following.

1. Enforceability concerns - The nonbinding and potentially nonconclusive nature of mediation is a major disincentive to parties who believe that they have a strong case. Paradoxically, when the parties once face a dispute, both sides tend to believe that they are righteous and should have a strong case (Fisher et al. 2011) and thus would refrain from mediating. In the mindset of some construction professionals, arbitration but not mediation has been regarded as the default way of ADR because the former could lead to an enforceable award. To address this concern, a thorough understanding of the settlement stage of mediation is useful and helpful. When settlement is reached between the parties, the mediator shall provide the parties a "Without Prejudice Mediation Agreement" for the parties to sign in good faith and with the mediator signing as a witness. This "Without Prejudice Mediation Agreement" is not legally binding and is subject to review by parties, which are encouraged to obtain independent legal advice in doing so. After review, the mediator shall provide the "Mediation Agreement" to the parties for signing, and that forms a legally binding contract for execution. These procedures effectively safeguard the enforceability of the mediated agreement.

2. Perception to compromise - Parties may have a perception of mediation that they would be compelled to compromise. This is a common misconception and misunderstanding of the voluntary and facilitative nature of mediation (Chee and Campbell 2016). In actuality, mediators shall never bias against either party, force the parties to compromise, or coerce the parties to settle. Greater input to education of the construction professionals and the community at large about the various aspects of mediation is required, so as to foster correct understanding of mediation. Proper accreditation systems and continuous professional development for mediators are also necessary in order to ensure the competence as well as keep up the standard of mediators.

3. Reluctance of public sector-Public sector officials may be reluctant to move toward a settlement for which they will be held accountable. In addition, the government officers representing the party may not have sufficient authority to settle the dispute. These are the main reasons that mediation of disputes arising from public works contracts between public client and contractors takes place less frequently than that happening in the private sector (Chee and Campbell 2016). Nevertheless, it would still be desirable and advisable for the public sector in a dispute to undergo mediation, so as to achieve at least partial settlement of the disputes before referring the remaining unresolved issues to other adjudicative means of dispute resolution. In this regard, the incorporation of compulsory mediation clauses in public works contracts is highly recommended.

\section{Construction med-arb}

\subsection{Key features of construction med-arb}

Med-arb is the hybridization of mediation and arbitration and is essentially a combination of mediation and arbitration as a hybrid mechanism of dispute resolution. The disputing parties first attempt to settle the matter by mediation. If mediation does not result in a settlement, the dispute resolution agreement provides for the mediator to be appointed as arbitrator and for him/her to proceed to resolve the dispute through arbitration (Oghigian 2003). In Hong Kong, med-arb is an emerging ADR mechanism and has begun to receive appreciation (Mak 2005). As explicated in the preceding sections, specialization rather than generic treatment of construction dispute resolution is recommended by the authors. Likewise, specialized construction med-arb to tackle the sophistication and uniqueness of construction disputes is advocated.

To understand med-arb, knowledge of arbitration is essential. Basically, arbitration is a process by which a dispute between two or more parties as to their legal rights 
and liabilities is referred to and determined in a judicial manner, with binding effect, by the application of law by an independent neutral party (an arbitrator or arbitral tribunal) outside the courts (Chee 2006). The essential features of arbitration include consensual, confidential, and private process with party autonomy; judicial nature of proceedings; determinative, final, and legally binding process; limited intervention by courts; jurisdiction of arbitral tribunal primarily set out by terms of arbitration agreement; and case management by arbitral tribunal. Detailed explanation of construction arbitration can be found in relevant literatures (Eilenberg 2003; Chee 2006; Cheng and Soo 2013). Under the Hong Kong legislation, the conduct of arbitration has been regulated by the Arbitration Ordinance (Chapter 341) (Hong Kong Government 1997) until recently; this ordinance was repealed with the new Arbitration Ordinance (Chapter 609), which came into effect in 2014 (Hong Kong Government 2014).

As construction med-arb brings together the elements of both mediation and arbitration; it shares the key features of mediation in its mediation phase and shares the key features of arbitration in its arbitration phase.

\subsection{Pros and cons of construction med-arb}

Med-arb offers various advantages that give it an edge over conventional mediation and arbitration. These are noteworthy for construction professionals.

1. Time and cost savings - Med-arb provides the possibility to conclude a case after the mediation phase. In such circumstances, the time and cost incurred by the dispute resolution process would be equivalent to those of mediation. Even if arbitration is required in the med-arb process, the issues that need to be resolved would possibly be substantially narrowed after the mediation process, leaving only a few tough and complex issues to be arbitrated. Hence, the total time and cost expenditure would be less than arbitrating at the start. As speedy and low-cost resolution of construction disputes is highly appreciated, med-arb provides an attractive alternative compared to the prevailing arbitration process. Compared to mediation, med-arb can always yield a decision that effectively eliminates the time and cost required by subsequent dispute resolution processes in case the mediation fails.

2. Incentive to settle - In the med-arb process, if the disputing parties cannot reach an agreement in the mediation phase, the mediator will switch his/ her role to an arbitrator and issue an award, which might be unfavorable from either party's viewpoint. The uncertain results of arbitral award would provide incentive to the parties to settle the case in the mediation phase, wherein the outcome is more controllable and more likely to be endured. In this sense, the mediation phase of construction med-arb can be viewed as construction mediation with parties propelled by an additional incentive to settle.

3. Reduced uncertainties - Med-arb allows the parties to narrow down the disputing issues through the mediation phase, such that the uncertainties associated with the arbitral award can be partially or even fully excised. This would present a solution to the criticism of arbitration as being sometimes unpredictable. In addition, the reduced scope of arbitration would be welcomed by construction firms, which are obliged to allocate colossal resources after entering into arbitration.

4. Better-arbitrated decision - According to Kagel (1993), the arbitrated decision formulated in med-arb process tends to be more practicable compared to that after conventional arbitration, as the arbitrator is more informed from the mediation phase. Though this argument is subject to controversy centering on the potential biased position of the arbitrator, as presented later, parties in general would be in favor of the expedient decisions generated from the med-arb process.

However, med-arb is associated with the following drawbacks that construction personnel should pay attention to.

1. Confidentiality may be compromised - In accordance with the principles of mediation, all revealed information and documents are confidential. With such privilege, the individual party is motivated to disclose sensitive information in confidence to the mediator, who is prohibited from disclosing such information to the other party. However, during arbitration, the parties would be more refrained from disclosing sensitive information, which may provoke adverse inferences. As seemingly there is a conflict between the confidentiality of mediation and that of the ensuing arbitration, the confidentiality aspect of med-arb has been challenged by its critics (Landry 1996). In practice, the neutral party in med-arb must be fully aware of the confidentiality principles in mediation and in arbitration and perform his/her roles accordingly.

2. Bias of the neutral party - The switching of roles by the neutral party from a mediator to an arbitrator has raised 
concern regarding the development of personal bias on the case. In the mediation phase, the neutral party, who is aware of his/her power to rule the case in the subsequent phase, might be sufficiently biased to exert pressure on the parties based on his/her personal view. However, in the arbitration phase, the neutral party, who has been exposed to the information disclosed during the previous mediation phase and caucuses with parties, might be biased from the legal rights-based position. The avoidance of such biases rests solely on the competence and self-discipline of the neutral party, who is subject to very high requirement as being both mediator and arbitrator of the same case.

3. Lack of market awareness - Med-arb and construction med-arb are relatively new to the Hong Kong market. At present, med-arb is rarely practiced in Hong Kong, and med-arb clauses have not been incorporated into standard conditions of construction contracts. This is also true in many parts of the world. Many construction professionals are not aware of med-arb or have only limited knowledge of med-arb. Furthermore, the availability of specialized construction "med-arbiters" who possess vast experience in construction, mediation, and arbitration is not sufficient. These factors limit the development of construction med-arb in Hong Kong and elsewhere. More efforts on educating the construction industry about med-arb, as well as more training and formal accreditation of construction med-arb professionals so as to generate and to meet market needs, are required. Furthermore, provision of a med-arb clause in construction contracts is recommended.

\section{Conclusions}

Characterized by the vast adoption of multilevel subcontracting systems, the existence of multiple contracting parties and stakeholders, various contractual arrangements and measurement methods, prevalence of power differences, sizeable scale of projects, and pervasion of technical knowledge and expertise, the construction industry is recognized as a unique profession that needs and warrants specialized dispute resolution mechanisms. To tackle construction disputes that may fall into one or more of different types, such as contractual, commercial, technical, professional, and legal aspects, and that may entail claims in terms of time, cost, and other elements, construction mediation and med-arb have been identified as having good prospects in resolving construction disputes.
Key features of mediation, including its voluntary, nonbinding, confidential, private, neutral, facilitative, structured, nonprejudicial, interest-based, and nonadjudicative nature, have been elaborated. The history of development of construction mediation in Hong Kong has been briefly reviewed. The pros and cons of mediation with special reference to the construction industry have been elucidated. Basically, construction mediation offers the merits of time and cost savings, coverage of parties' interests, facilitated communication, high degrees of privacy and party autonomy, sustainability of relationships, and promotion of win-win results. However, construction mediation is associated with problems, including enforceability concerns, perception of compromise, and reluctance of the public sector. These demerits may be mitigated by appropriate actions and practices.

As a hybrid dispute resolution mechanism that is emerging in Hong Kong, the nature and key features of med-arb (mediation-arbitration) have been introduced. The pros and cons of med-arb with special reference to the Hong Kong construction industry have been discussed. The strong points of med-arb include time and cost savings, incentive to settle, reduced uncertainties, and better-arbitrated decisions. On the other hand, med-arb is associated with drawbacks, including the possibility that confidentiality may be compromised, bias of the neutral party, and lack of market awareness.

If a dispute arises and if the dispute cannot be settled through negotiation, in standard med-arb, the parties involved, e.g., the Employer and the Contractor, first submit themselves to the mediation process and settle as many issues as they can. Those issues that are not settled through the mediation process are then settled through the arbitration process, wherein the med-arbiter renders an arbitral award similar to a verdict or a decision from a judge. Compared to mediation, med-arb can always yield a decision, which effectively eliminates the time and cost required by subsequent dispute resolution processes in case the mediation fails.

Greater input to education of construction professionals about med-arb, extensive training of competent construction med-arbiters, and incorporation of med-arb clauses in construction contracts are strongly advocated.

\section{References}

Banaitienè, N., \& Banaitis, A. (2012). Construction Project Management. Technika, Vilnius, Lithuania, 217pp.

Chau, K. W. (2007). Insight into resolving construction disputes by mediation/adjudication in Hong Kong. Journal of Professional 
Issues in Engineering Education and Practice, American Society of Civil Engineers, 133(2), pp. 143-147.

Chee, S. W. H. (2006). Setting arbitration in Hong Kong as the preferred dispute resolution centre for disputing arising in PRC. MA thesis, City University of Hong Kong, Hong Kong, 122pp.

Chee, S. W. H. (2013). From right to interest - specialised facilitative mediation (construction). JSD thesis, City University of Hong Kong, Hong Kong, 555pp.

Chee, S. W. H., \& Campbell, J. (2016). Construction Dispute Prevention and Resolution in Hong Kong 2016. Sweet \& Maxwell, Hong Kong.

Cheng, T. Y. W., \& Soo, G. K. L. (2013). Construction Law and Practice in Hong Kong, 3rd edn. Sweet \& Maxwell, Hong Kong, 809pp.

Cheung, S. O. (2014). Construction Dispute Research: Conceptualisation, Avoidance and Resolution. Springer International Publishing, Switzerland, 410pp.

Construction Industry Council. (2015). Reference Materials for Application of Dispute Resolution in Construction Contracts, Version 2. Construction Industry Council, Hong Kong, 112pp.

Eilenberg, I. M. (2003). Dispute Resolution in Construction Management. UNSW Press, Sydney, Australia, 196pp.

Fisher, R., Ury, W., \& Patton, B. (2011). Getting to Yes: Negotiating Agreement without Giving in, 3rd edn. Penguin, New York, USA, 204pp.

Hong Kong Government. (1984). Administrative Guidelines for the Trial Mediation Scheme. Lands \& Works Branch Technical Circular No. 10/84. Hong Kong Government, Hong Kong.

Hong Kong Government. (1985). General Conditions of Contract for Civil Engineering Works, 1985 Edition. Hong Kong Government, Hong Kong.

Hong Kong Government. (1989). Administrative Guidelines for Mediation in Construction Disputes. Lands \& Works Branch Technical Circular No. 8/89. Hong Kong Government, Hong Kong.

Hong Kong Government. (1991). Hong Kong Government Mediation Rules. Hong Kong Government, Hong Kong.

Hong Kong Government. (1993). General Conditions of Contract for Civil Engineering Works, 1993 Edition. Hong Kong Government, Hong Kong.

Hong Kong Government. (1997). Hong Kong Law Chapter 341: Arbitration Ordinance. Hong Kong Judiciary, Hong Kong.

Hong Kong Government. (1999). General Conditions of Contract for Civil Engineering Works, 1999 Edition. Hong Kong Government, Hong Kong.
Hong Kong Government. (2013). Hong Kong Law Chapter 620: Mediation Ordinance. Hong Kong Judiciary, Hong Kong.

Hong Kong Government. (2014). Hong Kong Law Chapter 609: Arbitration Ordinance. Hong Kong Judiciary, Hong Kong.

Hong Kong Institute of Architects, Hong Kong Institute of Construction Managers, Hong Kong Institute of Surveyors. (2005). Agreement \& Schedule of Conditions of Building Contract for Use in the Hong Kong Special Administrative Region. Hong Kong Institute of Architects, Hong Kong Institute of Construction Managers, Hong Kong Institute of Surveyors, Hong Kong.

Kagel, J. (1993). Mediating grievances. In: Gruenberg, G. W. (ed.), Arbitration 1993: The Changing Competitive Environment and Arbitration, Proceedings of the 46th Annual Meeting of the National Academy of Arbitrators, Washington, DC, USA. Bureau of National Affairs, Washington, DC, USA, pp. 76-89.

Kaklauskas, A., Kersuliene, V., \& Urbanaviciene, V. (2008). Determination of rational method for resolution of disputes with the help of multi-criteria negotiation decision support system for real estate. In: Proceedings of the 25th International Symposium on Automatic and Robotics in Construction, Vilnius, Lithuania. Elsevier, Amsterdam, The Netherlands, pp. 585-591.

Kumaraswamy, M. M. (1998). Consequences of construction conflict: A Hong Kong perspective. Journal of Management in Engineering, American Society of Civil Engineers, 14(3), pp. 66-74.

Kumaraswamy, M. M., \& Soo, G. K. L. (2010). Mediation - past, present, and prospects: Hong Kong perspective. Journal of Legal Affairs and Dispute Resolution in Engineering and Construction, American Society of Civil Engineers, 2(4), pp. 194-197.

Landry, S. (1996). Med-Arb: Mediation with a bite and an effective ADR model. Defense Counsel Journal, 63(2), pp. 263-269.

Levin, P. (2016). Construction Contract Claims, Changes, and Dispute Resolution. American Society of Civil Engineers, Reston, VA, USA, 477pp.

Mak, A. (2005). Whether it is viable to widely adopt the practice of mediation-arbitration ("Med-Arb") in Hong Kong Special Administrative Region. MA dissertation, School of Law, City University of Hong Kong, Hong Kong, 69pp.

Oghigian, H. (2003). The mediation/arbitration hybrid. Journal of International Arbitration, 20(1), pp. 75-80.

Richbell, D. (2008). Mediation of Construction Disputes. Blackwell Publishing, Oxford, UK, 175pp. 